\title{
Optimization design of fertilizer apparatus owned arc gears based on discrete element method
}

\author{
Guoqiang Dun ${ }^{1 *}$, Zhiyong $\mathrm{Gao}^{2}$, Yuxuan $\mathrm{Liu}^{1}$, Wenyi $\mathrm{ji}^{3}$, Ning Mao ${ }^{1}$, Xingpeng $\mathrm{Wu}^{1}$, Wenhui $\mathrm{Liu}^{1}$ \\ (1. College of Mechanical and Electrical Engineering, Northeast Forestry University, Harbin 150040, China; \\ 2. College of Engineering and Technology, Northeast Forestry University, Harbin 150040, China; \\ 3. College of Engineering, Northeast Agricultural University, Harbin 150030, China)
}

\begin{abstract}
To improve the uniformity of the flow when fertilizer apparatus discharges fertilizer, a kind of fertilizer apparatus owned arc gears was designed. Also, the design and working principle of its general structure and key components were analyzed theoretically. Aiming at exploring the influence of arc structural parameters to the performance of arc gears discharging fertilizer, DEM simulation was used in this study. Fertilizer apparatus owned arc gears was taken as the research object to analyze the influence of two key components including the arc radius of gears' concave-grooves and the minimal length between two mutual meshing gears. The variation coefficient of fertilizer discharging amount stability and the linear determined coefficient of fertilizer discharging amount in unit time as evaluation index were selected. Two factors and five levels quadratic rotation orthogonal experiment was applied, and Design-Expert 8.0 software was used to achieve data processing and analysis. The results of experiment indicated that the arc radius of gears' concave-grooves had significant effect on the linear determined coefficient of fertilizer discharging amount in unit time, and the minimal length between two mutual meshing gears had significant effect on the variation coefficient of fertilizer discharging amount stability. The optimum structural parameters were $8.54 \mathrm{~mm}$ as the arc radius of gears' concave-grooves and $5.22 \mathrm{~mm}$ as the minimal length between two mutual meshing gears. Upon this circumstance, the variation coefficient was 0.28 and determination coefficient was 0.9972. The optimum apparatus was selected to conduct the bench test and field simulation test. The results indicated that the variation coefficient is 0.27 , and the linear determined coefficient of is 0.9980 . The results of simulation experiment were anastomotic basically with the real result, which showed that DEM simulation technology was usable to the experiment of testing fertilizer discharging. The results of this research can provide a reference to the improving of performance in discharging fertilizer.
\end{abstract}

Keywords: agricultural machinery, fertilizer apparatus, discrete element method, experiment, structure parameter, fertilizing performance

DOI: $10.25165 /$ j.ijabe.20211402.5719

Citation: Dun G Q, Gao Z Y, Liu Y X, Ji W Y, Mao N, Wu X P, et al. Optimization design of fertilizer apparatus owned arc gears based on discrete element method. Int J Agric \& Biol Eng, 2021; 14(2): 97-105.

\section{Introduction}

Applying fertilizer is an important process in agricultural production, and unreasonable application can affect the nutrient absorption of crops, as well as results in some bad influences such as soil degradation, fertility decline and harden of soil, which are bad for the development of agriculture ${ }^{[1,2]}$. The fertilizer apparatus is a kind of important mechanical part in the process of applying fertilizer, and the work performance of devices has a significant impact on the result of fertilization process. At present,

Received date: 2020-02-09 Accepted date: 2020-10-10

Biographies: Zhiyong Gao, Undergraduate student, research interests: agricultural mechanization and automation, Email: gaogzy99@163.com; Yuxuan Liu, MS candidate, research interests: industrial design, Email: 910865556@qq.com; Wenyi Ji, PhD, research interests: mechanization and automation, Email: 1322642983@qq.com; Ning Mao, MS candidate, research interests: agricultural machinery and equipment, Email: 76174408@qq.com; Xingpeng Wu, MS candidate, research interests: agricultural machinery and equipment, Email: 1052795452@qq.com; Wenhui Liu, MS candidate, research interests: agricultural machinery and equipment, Email: 1095269772@qq.com.

*Corresponding author: Guoqiang Dun, $\mathrm{PhD}$, Lecturer, research interests: agricultural equipment and machinery. Northeast Forestry University, College of Mechanical and Electrical Engineering, Harbin 150040, China. Email: dunguoqiang1986@163.com. the major fertilizer apparatus in market is outer groove-wheel fertilizer apparatus, however, as the influence of some elements such as the groove ridge structure of fertilizer wheel and irregular size of fertilizer particle, outer groove-wheel fertilizer apparatus occurs frequently the phenomenon such as uneven fertilizer amount and "broken flow"[3,4].

At present, many researches aiming at outer groove-wheel fertilizer apparatus mainly include the influence of structural parameters and working parameters of them to the performance of discharging: Dun et al. ${ }^{[5,6]}$ used the discrete element software (EDEM) to analyze the influence of the parameters of the chamfer mechanism of the fertilizer discharge tongue of the outer-fluted fertilizer apparatus on the uniformity of fertilizer discharging; Yang et al. ${ }^{[7]}$ used the EDEM and 3D printing technology to analyze the influence of the parameters of the groove radius, spiral angle and rotation speed of the outer-fluted fertilizer apparatus on the fertilizer discharging; Zhang et al. ${ }^{[8]}$ obtained the influence of different working wheel length of outer-fluted fertilizer wheel to fertilizer discharging amount by simulating the fertilizer discharging process of the outer-fluted fertilizer apparatus. Wang et al. ${ }^{[9,10]}$ analyzed the influence of the working wheel length, the rotation speed and the opening angle of the fertilizer discharging tongue on the uniformity of fertilizer discharging and optimized the parameters according to the result analysis; Lv et al. ${ }^{[11,12]}$ used their 
own developed discrete element simulation software to simulate the movement state and fertilizer discharging characteristics of the fertilizer particle of the outer-fluted fertilizer apparatus. Now, most of researches are aiming at optimizing the structural parameters of outer groove-wheel fertilizer apparatus, which cannot avoid a problem, that is the groove and ridge structure of fertilizer apparatus wheel causes the bad flow uniformity. Therefore, designing the new-type fertilizer apparatus and promoting the flow uniformity have a greatly important significance.

Therefore, this research designed a kind of fertilizer apparatus owned arc gears which can promote the flow uniformity when discharges fertilizer. Through the structural design and theoretical analysis to fertilizer apparatus, we confirmed the elements that affect fertilizer discharging amount of the fertilizer apparatus owned arc gears, designed the two factors and five levels quadratic rotation orthogonal experiment, and applied the DEM simulation to analyze the discharging situations of the fertilizer apparatus in different parameters. Besides, the optimum structure was selected to do the bench test and field simulation test, which were hoped to offer reference to the optimizing of structural parameters and increasing of flow uniformity.

\section{Theoretical model in discrete element method}

The discrete element method can transmit the force between particles to analyze the stress condition between models according to the motility and the crash between particle ${ }^{[13]}$. The process that describes crash with the discrete element method is just the process of the production and reaction of contacting. When the fertilizer apparatus is working, a number of fertilizer particles rub and crash mutually, which is suitable to soft-sphere analysis theory in the discrete element method. Therefore, the soft-sphere contact model was used in this research ${ }^{[14-16]}$. Considering that there is no adhesive property in ordinary fertilizer, so the Hertz-Mindlin (no slip) contact model was used ${ }^{[17]}$.

\subsection{Theory analysis to soft-sphere contact model}

As is shown in Figure 1, it represents the contact way between soft-sphere particle model by damped vibration of spring ${ }^{[18]}$, and its motion equation is

$$
m x^{\prime \prime}+c x^{\prime}+k x=0
$$

where, $x$ is the displacement that deviates from the balance position, $\mathrm{m} ; m$ is the mass, $\mathrm{kg} ; c$ and $k$ are spring damping coefficient $(\mathrm{N} \cdot \mathrm{s} / \mathrm{m})$ and elastic coefficient $(\mathrm{N} / \mathrm{m})$, respectively.

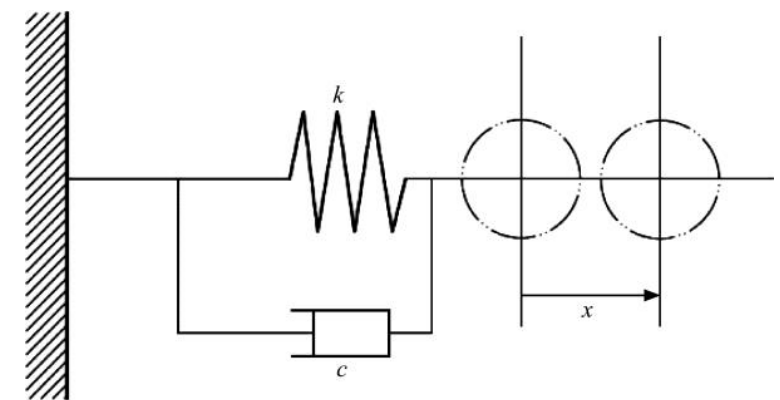

Figure 1 System of spring, damping and oscillator

The contact force can be broken down into two parts, as shown in Figure 2. The relationship between the particle and the contact wall is shown on the left. The relationship between particles is shown on the right. Each particle motion includes translation and rotation. When particles collide with each other, the relative motion between the contacting entities can be decomposed into normal motion and tangential motion. Normal motion can be simplified as a spring-damped system. Tangential motion can be simplified as a spring-damped-sliding friction system.

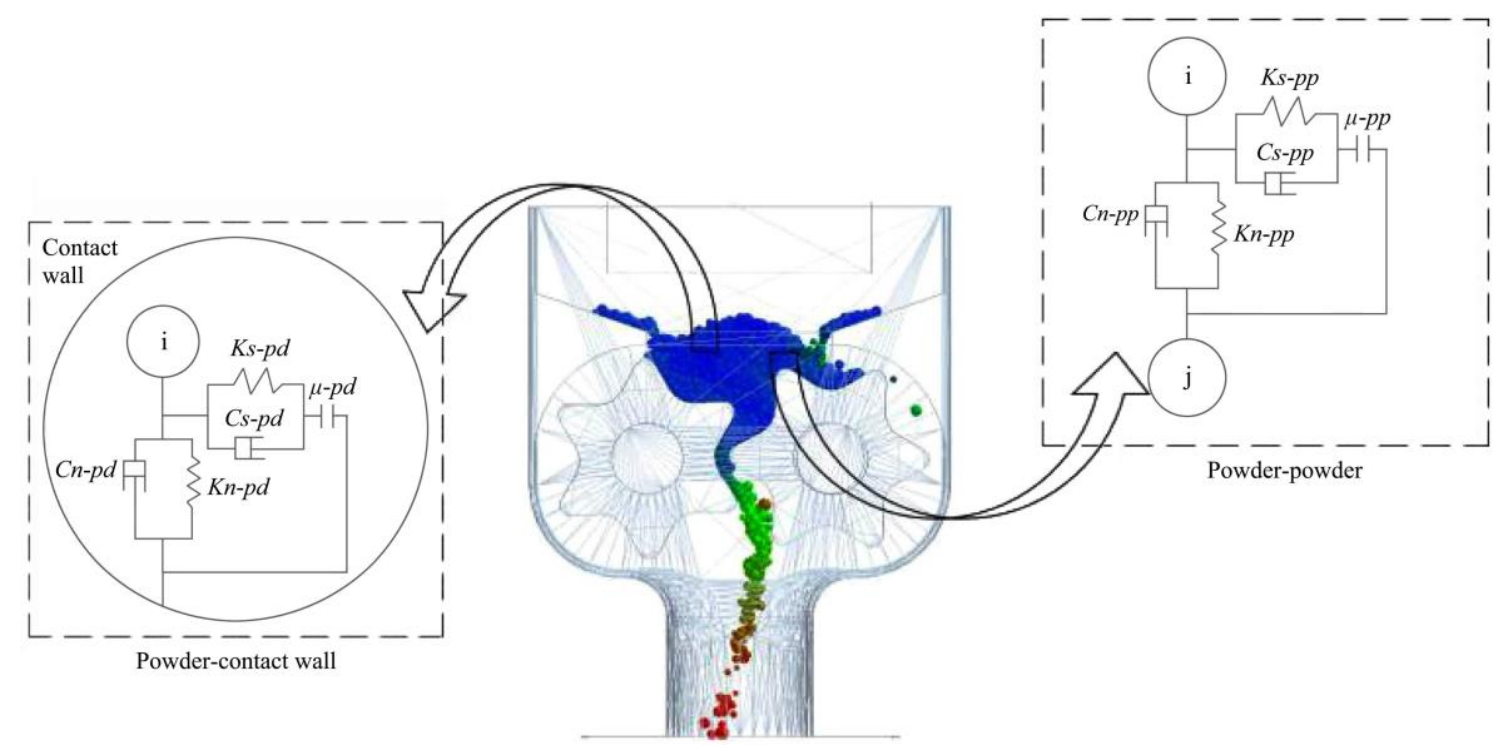

Figure 2 Simplifying treatment of soft-sphere model to contact forces between particles (or particle and wall)

\subsection{Theoretical analysis of Hertz-Mindlin (no slip) contact} model

The normal force $\left(F_{n}\right)$ in Hertz-Mindlin (no slip) contact model is applied in this research ${ }^{[19]}$ :

$$
F_{n}=\frac{4}{3} E^{*} \sqrt{R^{*}} \alpha^{\frac{3}{2}}
$$

where, $E^{*}$ is equivalent elasticity modulus, MPa; $R^{*}$ is equivalent radius of particle, $\mathrm{m}$; and $\alpha$ is the contact radius, $\mathrm{m}$.

Among them, the calculation of equivalent elasticity modulus is in Equation (3):

$$
\frac{1}{E^{*}}=\frac{1-\mu_{1}^{2}}{E_{1}}+\frac{1-\mu_{2}^{2}}{E_{2}}
$$

where, $E_{1}, \mu_{1}, E_{2}, \mu_{2}$ are the elasticity modulus and passion ratio of particle $i$ and particle $j$ respectively.

The tangential force in particle:

$$
F_{t}=-S_{t} \delta
$$

In this equation, $\delta$ is tangential overlap, and $S_{\mathrm{t}}$ is tangential stiffness.

The tangential stiffness is acquired from the below equation: 


$$
S_{t}=8 G^{*} \sqrt{R^{*} \alpha}
$$

where, $G^{*}$ is equivalent tangential elasticity, which is calculated from the following equation:

$$
\frac{1}{G^{*}}=\frac{2-\mu_{1}^{2}}{G_{1}}+\frac{2-\mu_{2}^{2}}{G_{2}}
$$

where, $G_{1}$ and $G_{2}$ are tangential elasticity of two particles.

\section{Analysis on structure of fertilizer apparatus}

The fertilizer apparatus owned arc gears was seemed as a model in this research, and the arc discharging gears model was established, and the relationship between structural parameters and fertilizer discharging amount was analyzed in this part.

\subsection{Structure of fertilizer apparatus}

The structure of fertilizer apparatus owned arc gears is composed by shell, arc discharging gears, initiative gear shaft, driven gear shaft and initiative six-party shaft hole, which are shown in Figure 3.

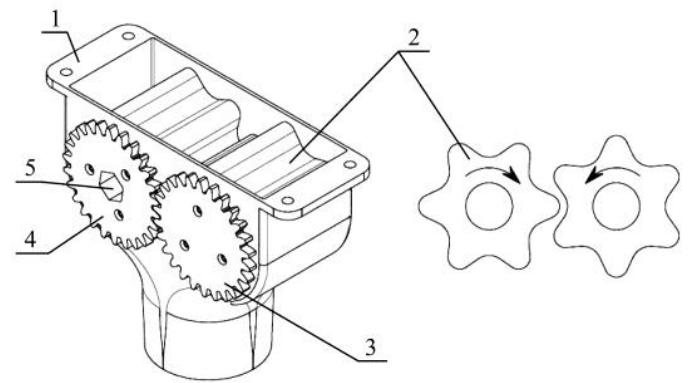

1. Shell 2. Arc discharging gears 3 . Driven gear shaft $\quad$ 4. Initiative gear shaft 5. Initiative six-party shaft hole

Figure 3 Structure graphic of fertilizer apparatus owned arc gears

Fertilizer apparatus controls fertilizer discharging amount by frequency transformer which can adjust the rotate speed of arc discharging gears; the initiative gear is turned by initiative six-party shaft which is controlled by electrical machinery, and two gear shafts transmit power through their rotation, and the gear shafts and the arc discharging gears are linked and transmitted by bolts.

Compared with the traditional outer groove-wheel fertilizer apparatus, fertilizer apparatus owned arc gears has the outstanding advantage of improving the uniformity of fertilizer discharging. When the groove structure of the outer groove-wheel fertilizer just reaches the fertilizer discharging tongue, the fertilizer in the former tank has dropped completely, resulting in the phenomenon of "broken flow"; when the groove structure all passes over the fertilizer discharge tongue, the fertilizer in the tank will accumulate and fall, thus causing uneven fertilizer discharge. The principle of the fertilizer apparatus owned arc gears is that the fertilizer is discharged through the clearance of the circular arc fertilizer discharging gear. The gap between the arc gear is stable, and the tooth space of the circular arc gear moves alternately continuously, which improves the uniformity of the fertilizer discharge flow and avoids the blocking and intermittent fertilizer discharging problems of the common fertilizer discharging device.

\subsection{Theoretical analysis of fertilizer apparatus structure}

To analyze the key structural parameters of fertilizer apparatus, the equation to calculate the total mass of discharging is as follow:

$$
m=\rho_{\mathrm{b}} V
$$

where, $m$ is the mass of discharging, $\mathrm{g} ; \rho_{\mathrm{b}}$ is the stacking density of fertilizer, $\mathrm{g} / \mathrm{mm}^{3} ; V$ is the volume of discharging, $\mathrm{mm}^{3}$.

From Equation (7), the mass of discharging $(m)$ is the product of the stacking density $\left(\rho_{\mathrm{b}}\right)$ and the volume of discharging $(V)$, and the stacking density $\left(\rho_{\mathrm{b}}\right)$ is the inherent attribute of fertilizer. Therefore, changing the volume of discharging $(V)$ can only change the mass of discharging $(m)$.

As shown in Figure 4, the volume of discharging $(V)$ can be calculated as follow:

$$
V=\frac{s d L \omega t}{60}
$$

where, $s$ is the minimal length between gears, $\mathrm{mm} ; d$ is the length of arc discharging gears' work slot, $\mathrm{mm} ; L$ is the length of one turn of gears, $\mathrm{mm} ; \omega$ is the speed of gears' turning, $\mathrm{r} / \mathrm{min}$; $t$ is the time of gears' turning, $\mathrm{s}$.

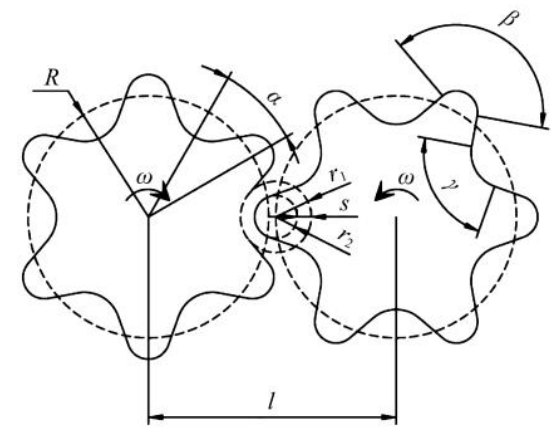

Figure 4 Graphic of design parameters of fertilizer apparatus

Among them, the minimal length between gears $(s)$ is:

$$
s=r_{1}-r_{2}
$$

where, $r_{1}$ is the arc radius of arc discharging gears, $\mathrm{mm} ; r_{2}$ is the arc radius of gears' round ridge, $\mathrm{mm}$.

A part of fertilizer apparatus owned arc gears in Figure 4 was intercepted, as shown in Figure 5. Arc discharging gears actually are constituted by arc $G B$ whose radius is $r_{1}$, arc $C F$ whose radius is $r_{2}$, and two common tangents $B C$ and $F I$, among them, $B C$ is equal-length with $F I$. Connect $A B, C D, A D, A O$ and $D O$, at the same time, $A D$ intersects with $B C$ on $E$. Define $\angle E A B$ as $\delta(\mathrm{rad})$ and $\angle D A O$ as $\theta(\mathrm{rad})$. Define $A E$ as $c_{1}(\mathrm{~mm}), D E$ as $c_{2}(\mathrm{~mm}), A D$ as $c(\mathrm{~mm}), B C$ as $a(\mathrm{~mm})$. From Figure 4, it's easy to know that $D O$ is equal to $R(\mathrm{~mm}), A O$ is equal to $l-R(\mathrm{~mm})$.

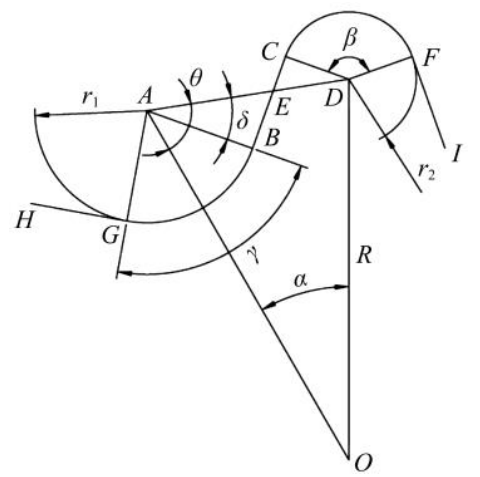

Figure 5 Graphic of parameters calculation

Combine the design of fertilizer apparatus owned arc gears with the basic parameters in Figure 5 to calculate the parameters of fertilizer rowing amount, and the equation is as follows:

The length $(L)$ of one revolution of the arc discharging gears is:

$$
L=z\left(r_{1} \gamma+r_{2} \beta+2 a\right)
$$

where, $z$ is the number of teeth; $\beta$ is central angle of arc discharging gears' round ridge arc, rad; $\gamma$ is the central angle of arc discharging gears' race arc, rad. Among them, the number of gears' teeth $z$ is

$$
z=\frac{\pi}{\alpha}
$$


where, $\alpha$ is the angle between the center of circle of round ridge arc and race arc, rad.

From geometrical relationship, it can be known that central angle of arc discharging gears' round ridge arc $(\beta)$ and the central angle of arc discharging gears' race $\operatorname{arc}(\gamma)$ are:

$$
\begin{gathered}
\beta=2(\alpha+\theta-\delta) \\
\gamma=2(\theta-\delta) \\
\delta=\arccos \frac{r_{1}}{r_{2}} \\
\theta=\arccos \frac{c^{2}+(l-R)^{2}-R^{2}}{2 c(l-R)} \\
c=c_{1}+c_{2}
\end{gathered}
$$

For $\triangle A O D$, there is:

$$
c^{2}=R^{2}+(l-R)^{2}-2 R(l-R) \cos \alpha
$$

For $\triangle A B E$ and $\triangle \mathrm{CDE}$, there are:

$$
\begin{gathered}
c_{1}=\frac{\frac{r_{1}}{r_{2}}}{1+\frac{r_{1}}{r_{2}}} c \\
c_{2}=\frac{1}{1+\frac{r_{1}}{r_{2}}} c
\end{gathered}
$$

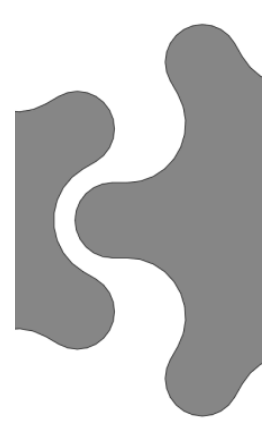

a. $r_{1}=11 \mathrm{~mm}, s=4 \mathrm{~mm}$

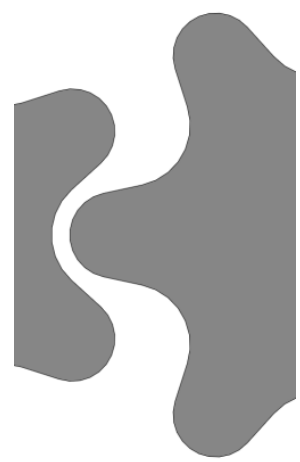

f. $r_{1}=10 \mathrm{~mm}, s=3 \mathrm{~mm}$

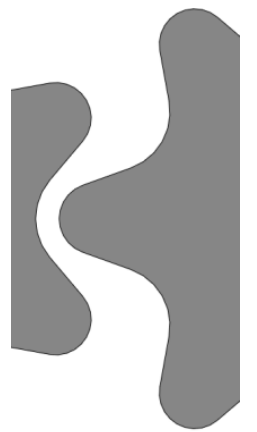

b. $r_{1}=10 \mathrm{~mm}, s=4 \mathrm{~mm}$

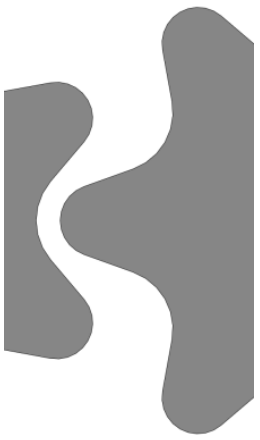

g. $r_{1}=10 \mathrm{~mm}, s=4 \mathrm{~mm}$

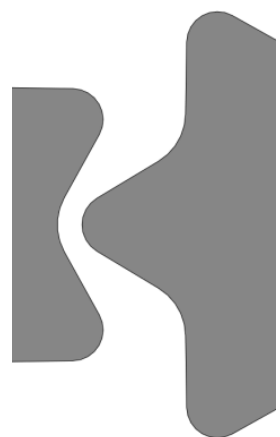

c. $r_{1}=9 \mathrm{~mm}, s=4 \mathrm{~mm}$

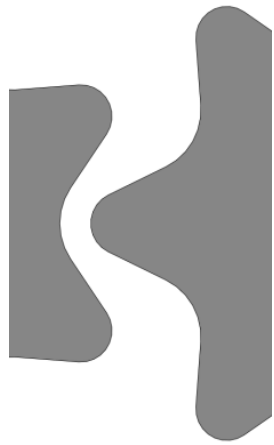

h. $r_{1}=10 \mathrm{~mm}, s=5 \mathrm{~mm}$
The length of common tangent $a$ is

$$
a=\sqrt{c_{1}^{2}-r_{1}^{2}}+\sqrt{c_{2}^{2}-r_{2}^{2}}
$$

For different application objects, it can be known from Equation (8) that the main arc structural parameters that affect the performance of fertilizer apparatus owned arc gears are the minimal length between two mutual meshing gears $(s)$, the working slot length of arc discharging gears $(d)$, and the length of one revolution of the arc discharging gears $(L)$. From Equations (10) to (20), it can be known that the length $(L)$ is decided by the number of teeth $(z)$, the center distance of two gears $(l)$, equivalent radius $(R)$, the arc radii of two gears' race $\left(r_{1}\right)$ and arc radius of gears' round ridge $\left(r_{2}\right)$ collectively. From Equation (9), it can be known that the minimal length between two mutual meshing gears $(s)$ is related with the arc radii of two gears' race $\left(r_{1}\right)$ and arc radius of gears' round ridge $\left(r_{2}\right)$. And the working slot length of arc discharging gears $(d)$ and the center distance of two gears $(l)$ are intrinsic parameters when product fertilizer apparatus owned arc gears.

To sum up, to explore the influence of structural parameters to the performance of discharging, $R=34 \mathrm{~mm}, l=70 \mathrm{~mm}, d=50 \mathrm{~mm}$ are chosen as the constant factors in this research, and the arc radius of two gears' race $\left(r_{1}\right)$ and the minimal length between two mutual meshing gears $(s)$ are chosen as the influence factors. As is shown in Figure 6.

Figure 6 The graphic of influences of $r_{1}, s$ on the shape of arc discharging gears

\section{DEM simulation experiment based on EDEM}

Discrete Element Method has been applied widely in industry and agriculture as analysis method to analyze effective particle movement ${ }^{[20-22]}$. As the following analysis, the arc radius of two gears' race $\left(r_{1}\right)$ and the minimal length between two mutual meshing gears $(s)$ were chosen to do simulation experiment in this research. This experiment was designed by single factor analysis and response surface design.

\subsection{Design of simulation experiment}

From the previous theoretical analysis in chapter 3, it can be known that the arc radius of two gears' race $\left(r_{1}\right)$ and the minimal length between two mutual meshing gears $(s)$ were chosen as the influence factors.

To explore the influence of two factors to performance of discharging, the relevant test program was designed ${ }^{[23]}$. To research the influence of the arc radius of two gears' race $\left(r_{1}\right)$ to performance of discharging, the rotate speed was designed as 
$40 \mathrm{r} / \mathrm{min}$, and the arc radius of two gears' race $\left(r_{1}\right)$ was set as experiment factor, then according the actual requirement, $r_{1}$ was chosen to be $7 \mathrm{~mm}, 8 \mathrm{~mm}, 9 \mathrm{~mm}, 10 \mathrm{~mm}$ and $11 \mathrm{~mm}$ to do five sets of experiments respectively, and each set repeated three times. To research the influence of the minimal length between two mutual meshing gears $(s)$ on the performance of discharging, the rotate speed was designed as $40 \mathrm{r} / \mathrm{min}$, and the minimal length between two mutual meshing gears $(s)$ was chosen as $3 \mathrm{~mm}, 4 \mathrm{~mm}, 5 \mathrm{~mm}$, $6 \mathrm{~mm}$ and $7 \mathrm{~mm}$ for five sets of experiment respectively, and each set also repeated three times. The grid bin group (a) whose thickness was $40 \mathrm{~mm}$ at the exit of fertilizer apparatus was set to reflect discharge uniformity of discharging by monitoring discharging stability variation coefficient $(\sigma)$, and the grid bin group (b) whose height was $40 \mathrm{~mm}$ at the bottom of fertilizer collector was also set to reflect discharging infirmity of fertilizer apparatus by monitoring the determination coefficient of fertilizer discharging amount in unit time $\left(r^{2}\right)$ of particle in grid.

\subsection{Establishing of fertilizer particle model}

Urea produced from Yankuang Lunan Chemical Fertilizer Plant, China was chosen as the experiment materials of DEM. 100 fertilizer particles were extracted randomly, and their 3-dimension sizes (length, width and height) were measured with vernier caliper (Shida 91512 digital display vernier caliper), and their weights were also measured with electronic balance (Huachao utp-313 electronic balance). The average value of length, width and height of them were $2.52 \mathrm{~mm}, 2.49 \mathrm{~mm}$ and $2.61 \mathrm{~mm}$, and the average weight of per particle was $0.011 \mathrm{~g}$. After statistics and calculation, the equivalent diameter of per urea particle was $2.54 \mathrm{~mm}$, and the density of urea was $1283 \mathrm{~g} / \mathrm{mm}^{3}$. As shown in Figure 7, in the particle factory of EDEM, the average radius of particle was set as $1.27 \mathrm{~mm}$, and the sizes of them obeyed normal distribution whose $\mu$ was 1.27 and $\sigma^{2}$ was 0.29 . The setting of parameters was shown in Table 1 .

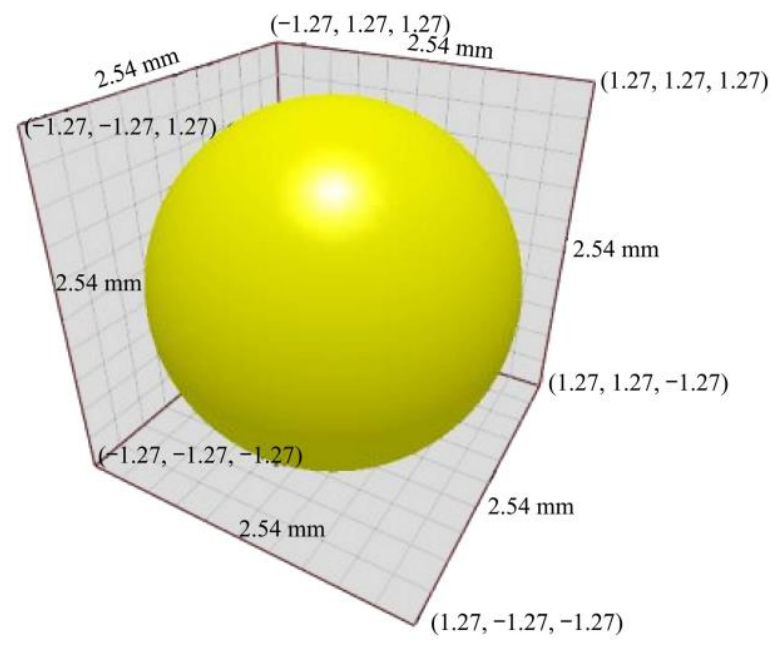

Figure 7 Model of fertilizer particle in EDEM

Table 1 Setting of particle parameter in EDEM

\begin{tabular}{ll}
\hline \multicolumn{1}{c}{ Particle parameters } & Value \\
\hline Average particle mass $/ \mathrm{g}$ & 0.011 \\
Average particle volume $/ \mathrm{mm}^{3}$ & 8.580 \\
Average particle radius $/ \mathrm{mm}$ & 1.270 \\
The standard deviation of particle radius $/ \mathrm{mm}$ & 0.290 \\
\hline
\end{tabular}

\subsection{Setting of contact parameters}

According the previous introduction in chapter 2.3, Hertz-Mindlin (no slip) model was applied as the contact model between urea particles, and also urea particles and fertilizer apparatus owned arc gears (its material is PVC). From related literatures, the specific parameters in EDEM are shown in Table 2.

Table 2 Setting of variables parameters in EDEM

\begin{tabular}{|c|c|c|c|}
\hline Items & Particle property & Value & Source \\
\hline \multirow{3}{*}{ Fertilizer particle } & Poisson's ratio & 0.51 & \multirow{3}{*}[24]{} \\
\hline & Shear modulus/MPa & 28 & \\
\hline & Density $/ \mathrm{kg} \cdot \mathrm{m}^{-3}$ & 1283 & \\
\hline \multirow{3}{*}{ Fertilizer apparatus } & Poisson's ratio & 0.43 & \multirow{3}{*}[25]{} \\
\hline & Shear modulus/MPa & 1500 & \\
\hline & Density $/ \mathrm{kg} \cdot \mathrm{m}^{-3}$ & 1418 & \\
\hline \multirow{3}{*}{ Particle to particle } & Coefficient of restitution & 0.28 & \multirow{3}{*}[25]{} \\
\hline & Coefficient of static friction & 0.36 & \\
\hline & Coefficient of rolling friction & 0.15 & \\
\hline \multirow{3}{*}{$\begin{array}{c}\text { Particle to Fertilizer } \\
\text { apparatus }\end{array}$} & Coefficient of restitution & 0.36 & \multirow{3}{*}[25]{} \\
\hline & Coefficient of static friction & 0.41 & \\
\hline & Coefficient of rolling friction & 0.04 & \\
\hline
\end{tabular}

4.4 Establishment and importing of the geometric model

Solidworks (Version 2016) was used to design and establish the fertilizer apparatus owned arc gears and 3D model. The unnecessary and non-contacting structure were removed and saved as .step file. The .step file was imported into EDEM software, and the parameters of model part were set. Rotation speed for arc discharging gears was set, as well as the particle factory where the total number of produced particle was 3000 and the target number per second of produced particle was 30000 . The simulation model is shown in Figure 8.

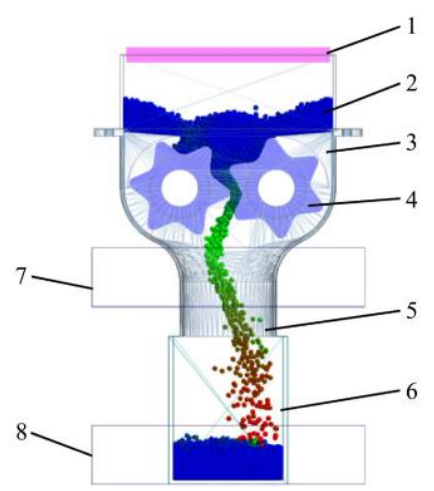

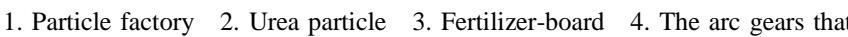
discharges fertilizer 5. The box of fertilizer apparatus 6. Particle collector 7. Grid bin group (a) 8 . Grid bin group (b)

Figure 8 Model of simulation geometry

\subsection{Setting of simulating calculation}

The Rayleigh Time Step was set as $5 \times 10^{-6} \mathrm{~s}$, and the total time of simulation was $3 \mathrm{~s}$. The target save interval of date logging was $0.01 \mathrm{~s}$, and the simulator cell size was set as $3 R_{\min }$.

\section{Experiment design based on response surface}

Response surface methodology (RSM) is the method that can achieve mathematical modeling analysis for multivariable problems in mathematical and statistical method, also can acquire the optimal technological conditions or parameters ${ }^{[26]}$.

The discharging stability variation coefficient $(\sigma)$ in grid bin group (a) and the determination coefficient of fertilizer discharging amount in unit time $\left(r^{2}\right)$ grid bin group (b) were set as experiment indicators to do the response surface experiment.

\subsection{Evaluation index of discharging uniformity}

According to the previous introduction in Section 4.1, the grid 
bin group (a) was set at the exit of fertilizer apparatus, and the time range of output line graph was set as 0.3 to $2.0 \mathrm{~s}$ in the post-processing module of EDEM, and the primary attribute of $y$-axis was set as mass, which is shown in Figure 9. The discharging stability variation coefficient $(\sigma)$ in grid bin group (a) reflects the uniformity of discharging, which is shown in Equations (21)-(23).

$$
\bar{m}=\frac{1}{n} \sum m_{i}
$$

where, $\bar{m}$ is the average mass of fertilizer particle through grid bin group (a) in $0.3 \mathrm{~s}$ to $2 \mathrm{~s}(\mathrm{~g}) ; n$ are time intervals; $m_{i}$ is the mass of fertilizer through grid bin group (a) in the $i$-th $(i=1,2, \ldots, n)$ time interval.

$$
s=\sqrt{\frac{1}{n-1}\left(m_{i}-\bar{m}\right)^{2}}
$$

where, $s$ is standard deviation of fertilizer mass of grid bin group (a) during 0.3-2.0 s, g.

$$
\sigma=\frac{s}{\bar{m}}
$$

where, $\sigma$ is the variable coefficient of fertilizer mass of grid bin group (a) during 0.3-2.0 s.

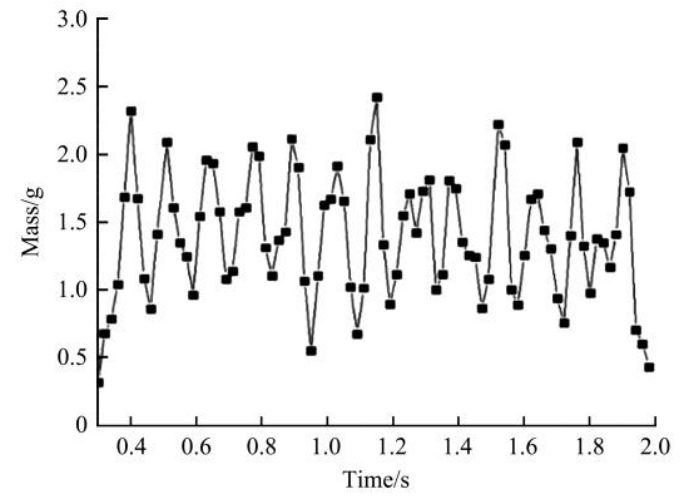

Figure 9 Fertilizer particle changing graphic from grid bin group (a) in single experiment

In experiments, the grid bin group (b) was set at the bottom of fertilizer collector. In the post-processing module in EDEM, the time range of exporting line graph was set as 0.3 to $2.0 \mathrm{~s}$, and the primary attribute of $y$-axis was set as mass, which are shown in Figure 10. The rotate speed of gears was set as 20, 40, 60, 80 and $100 \mathrm{r} / \mathrm{min}$ respectively in each group, and three simulation tests were repeated to reflect the uniformity of discharging with the determination coefficient of fertilizer discharging amount in unit time $\left(r^{2}\right)$ in grid bin group (b) in different rotate speed, which is shown in Equations (24) and (25).

$$
y_{i}=\frac{m_{i \max }-m_{i \min }}{\Delta t_{i}}
$$

In Equation (24), $i(i=1,2,3,4,5)$ are the experiments in the conditions that rotate speed were $20 \mathrm{r} / \mathrm{min}, 40 \mathrm{r} / \mathrm{min}, 60 \mathrm{r} / \mathrm{min}, 80$ $\mathrm{r} / \mathrm{min}$ and $100 \mathrm{r} / \mathrm{min}$, respectively; $y_{i}$ is fertilizer discharging amount in each unit time in $i$-th experiment, $\mathrm{g} / \mathrm{s} ; m_{\text {imax }}$ is the maximum deposit volume of fertilizer at $0.3-2.0 \mathrm{~s}$ in $i$-th experiment, $\mathrm{g} ; m_{i \min }$ is the minimum deposit volume of fertilizer at $0.3-2.0 \mathrm{~s}$ in $i$-th experiment $(\mathrm{g}), \Delta t_{i}$ is the time difference in simulation in $i$-th experiment, $\mathrm{s}$; and here, $\Delta t_{i}$ is $1.7 \mathrm{~s}$.

$$
r^{2}=\frac{S S R}{S S T}
$$

where, $r^{2}$ is determined coefficient; SSR is regression sum of squares of data, and SST is the total sum of squares.

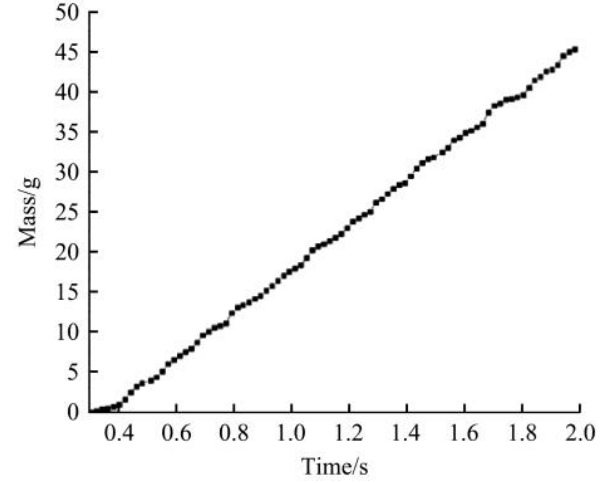

Figure 10 Amount of fertilizer accumulation changing graphic from grid bin group (b) in single experiment

\subsection{Experiment method and results}

To explore the influence of arc structural parameters to fertilizer performance of fertilizer apparatus owned arc gears, the arc radius of gears' concave-grooves $\left(r_{1}\right)$ and the minimal length between two mutual meshing gears $(s)$ were chosen as the influence factors. The two factors and five levels quadratic rotation orthogonal experiment was applied, and Design-Expert 8.0 software was used to do data processing ${ }^{[27]}$, then the structural parameters of gears in the condition of the most uniform fertilizer discharging amount was optimized, which were shown in Table 3 and Table 4.

Table 3 Code table of experimental factor level

\begin{tabular}{ccc}
\hline & \multicolumn{2}{c}{ Experiment factors } \\
\cline { 2 - 3 } & $\begin{array}{c}\text { The arc radius of gears' } \\
\text { concave-grooves } r_{1} / \mathrm{mm}\end{array}$ & $\begin{array}{c}\text { The minimal length between two } \\
\text { mutual meshing gears } s / \mathrm{mm}\end{array}$ \\
\hline$+\gamma$ & 11 & 7 \\
+1 & 10 & 7 \\
0 & 9 & 5 \\
-1 & 8 & 4 \\
$-\gamma$ & 7 & 3 \\
\hline
\end{tabular}

Table 4 Experimental scheme and results of quadratic orthogonal rotary

\begin{tabular}{ccccc}
\hline & \multicolumn{2}{c}{ Independent variable } & \multicolumn{2}{c}{ Test indicators } \\
\cline { 2 - 5 } Test number & $x_{1}$ & $x_{2}$ & $\sigma$ & $r^{2}$ \\
\hline 1 & -1 & -1 & 0.399 & 0.9951 \\
2 & 1 & -1 & 0.470 & 0.9835 \\
3 & -1 & 1 & 0.482 & 0.9938 \\
4 & 1 & 1 & 0.295 & 0.9853 \\
5 & -1.414 & 0 & 0.356 & 0.9938 \\
6 & 1.414 & 0 & 0.364 & 0.9782 \\
7 & 0 & -1.414 & 0.670 & 0.9980 \\
8 & 0 & 1.414 & 0.377 & 0.9908 \\
9 & 0 & 0 & 0.324 & 0.9954 \\
10 & 0 & 0 & 0.274 & 0.9969 \\
11 & 0 & 0 & 0.296 & 0.9939 \\
12 & 0 & 0 & 0.272 & 0.9987 \\
13 & 0 & 0 & 0.300 & 0.9985 \\
14 & 0 & 0 & 0.261 & 0.9969 \\
15 & 0 & 0 & 0.297 & 0.9914 \\
16 & 0 & 0 & 0.264 & 0.9986 \\
\hline
\end{tabular}

\section{Analysis of experimental results}

6.1 Variance analysis of discharging stability variation coefficient in grid bin group (a)

According to the experiment data in Table 4, the variance 
analysis results of the discharging stability variation coefficient $(\sigma)$ in grid bin group (a) from Design-Expert 8.0 software was shown in Table 5. The relation between two divisors that affect $\sigma$ and performance index from which is shown in the following equation:

$$
\begin{aligned}
& y_{1}=0.29+2.825 \times 10^{-3} x_{1}-0.1 x_{2}-0.064 x_{1} x_{2}+ \\
& 0.029 x_{1}^{2}+0.11 x_{2}^{2}+0.08 x_{1}^{2} x_{2}-0.032 x_{1} x_{2}^{2}
\end{aligned}
$$

According to the analysis of variance in Table 5, the factor $x_{2}$ is extremely significant, and factors $x_{1} x_{2}, x_{2}{ }^{2}, x_{1}{ }^{2} x_{2}$ are significant at the level of $\alpha=0.05$, and the others are not significant.

Table 5 Variance analysis of each factor influence to discharging stability variation coefficient in grid bin group (a)

\begin{tabular}{cccccc}
\hline Source & $\begin{array}{c}\text { Sum of } \\
\text { squares }\end{array}$ & DoF & Mean square & $F$-value & $p$-value \\
\hline Model & 0.17 & 7 & 0.024 & 38.5 & $<0.0001$ \\
$x_{1}$ & $3.191 \times 10^{-5}$ & 1 & $3.191 \times 10^{-5}$ & 0.050 & 0.8281 \\
$x_{2}$ & 0.043 & 1 & 0.043 & 67.54 & $<0.0001$ \\
$x_{1} x_{2}$ & 0.017 & 1 & 0.017 & 26.12 & 0.0009 \\
$x_{1}{ }^{2}$ & $6.916 \times 10^{-3}$ & 1 & $6.916 \times 10^{-3}$ & 10.91 & 0.0108 \\
$x_{2}^{2}$ & 0.099 & 1 & 0.099 & 156.22 & $<0.0001$ \\
$x_{1}{ }^{2} x_{2}$ & 0.013 & 1 & 0.013 & 20.34 & 0.0020 \\
$x_{1} x_{2}^{2}$ & $2.021 \times 10^{-3}$ & 1 & $2.021 \times 10^{-3}$ & 3.19 & 0.1120 \\
Lack of fit & $5.07 \times 10^{-3}$ & 1 & $5.07 \times 10^{-3}$ & 3.87 & 0.0899 \\
Pure error & $1.805 \times 10^{-3}$ & 7 & $4.665 \times 10^{-4}$ & - & - \\
Cor total & 0.18 & 15 & - & - & - \\
\hline
\end{tabular}

Note: $p<0.01$ means extremely significant, $0.01<p<0.05$ means significant, $p>0.05$ means not significant. DoF means degree of freedom.

6.2 Variance analysis of determined coefficient of fertilizer discharging amount in unit time in grid bin group (b)

According to experiment data in Table 4, Table 6 shows variance analysis of determined coefficient of fertilizer discharging amount in unit time in grid bin group (b) through software Design-Expert 8.0. The relationship between two factors of determined coefficient of fertilizer discharging amount in unit time $\left(r^{2}\right)$ and performance index was obtained as follows:

$$
\begin{aligned}
& y_{2}=1-5.27 \times 10^{-3} x_{1}-1.201 \times 10^{-3} x_{2}+ \\
& 7.75 \times 10^{-4} x_{1} x_{2}-5.353 \times 10^{-3} x_{1}^{2}-1.141 x_{2}^{2}
\end{aligned}
$$

According to results of variance analysis from Table 6 , factor $x_{1}$ is extremely significant, factor $x_{1}^{2}$ is significant at the level of $\alpha=0.05$, and other factors are not significant.

Table 6 Variance analysis of each factor influence to the fertilizer mass in unit time of coefficient of determination in grid bin group (b)

\begin{tabular}{cccccc}
\hline Source & Sum of squares & DoF & Mean square & $F$-value & $p$-value \\
\hline Model & $4.758 \times 10^{-4}$ & 5 & $9.516 \times 10^{-5}$ & 15.15 & 0.0002 \\
$x_{1}$ & $2.222 \times 10^{-4}$ & 1 & $2.222 \times 10^{-4}$ & 35 & 0.0001 \\
$x_{2}$ & $1.115 \times 10^{-5}$ & 1 & $1.115 \times 10^{-5}$ & 36 & 0.2050 \\
$x_{1} x_{2}$ & $2.402 \times 10^{-6}$ & 1 & $2.402 \times 10^{-6}$ & 1.84 & 0.5502 \\
$x_{1}{ }^{2}$ & $2.292 \times 10^{-4}$ & 1 & $2.292 \times 10^{-4}$ & 0.38 & 0.0001 \\
$x_{2}{ }^{2}$ & $1.041 \times 10^{-5}$ & 1 & $1.041 \times 10^{-5}$ & 36.48 & 0.2271 \\
Lack of fit & $1.564 \times 10^{-5}$ & 3 & $5.215 \times 10^{-6}$ & 1.66 & 0.5446 \\
Pure error & $4.719 \times 10^{-5}$ & 7 & $6.741 \times 10^{-6}$ & 0.77 & - \\
Cor total & $5.386 \times 10^{-4}$ & 15 & - & - & - \\
\hline
\end{tabular}

Note: $p<0.01$ means extremely significant, $0.01<p<0.05$ means significant, $p>0.05$ means not significant.

6.3 Response surface analysis for discharging stability variation coefficient in grid bin group (a)

According to Figure 11, the minimal value of variation coefficient is 0.200 , and the trend of response surface in the direction of the arc radius of gears' concave-grooves is slow, and the variation coefficient increases at first then decreases along with value $\left(r_{1}\right)$ increasing; the trend of response surface in the direction of the minimal length between two mutual meshing gears is obvious. The variation coefficient decreases at first then increases along with value $s$ increasing. According to actual working state and Figure 6, clearance between two mutual meshing gears gets bigger when value $(s)$ is increasing, and most fertilizer will slip down because of alternate motion of concave-groove and wheel spinal, which leads to be heterogeneous. Fertilizer is not easy to be discharged when value $s$ is decreasing, which also causes inhomogeneous.

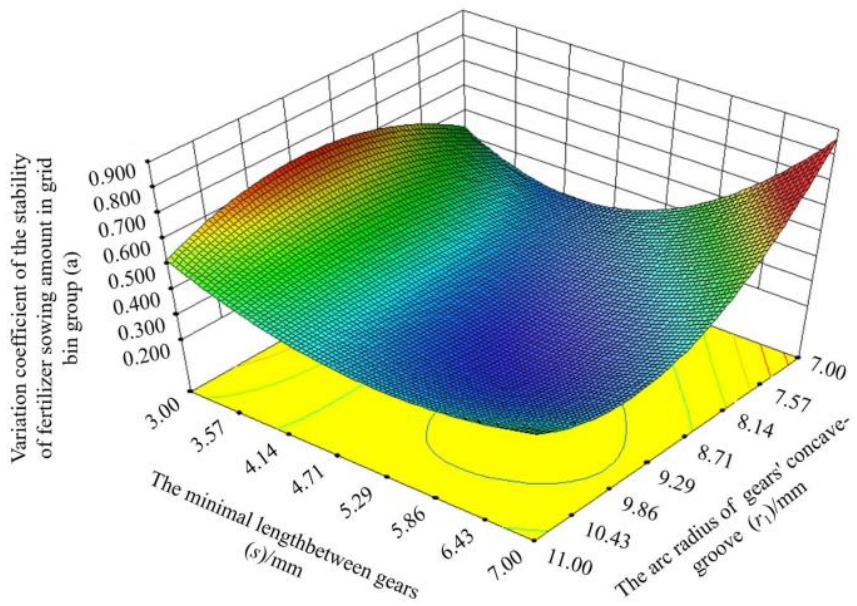

Figure 11 Response surface map of the minimal length between gears $(s)$ and the arc radius of gears' concave-groove $\left(r_{1}\right)$ to variation coefficient

6.4 Response surface analysis for the linear determined coefficient of fertilizer discharging amount in unit time in grid bin group (b)

According to Figure 12, the maximum value of linear determined coefficient of fertilizer discharging amount in unit time is 0.995 . The trend of response surface in the direction of the arc radius of gears' concave-grooves is obvious. The determined coefficient increases at first then decreases along with value $\left(r_{1}\right)$ increasing. The trend of response surface in the direction of the minimal length between two mutual meshing gears is slower. The determined coefficient increases at first then decreases along with value $(s)$ increasing.

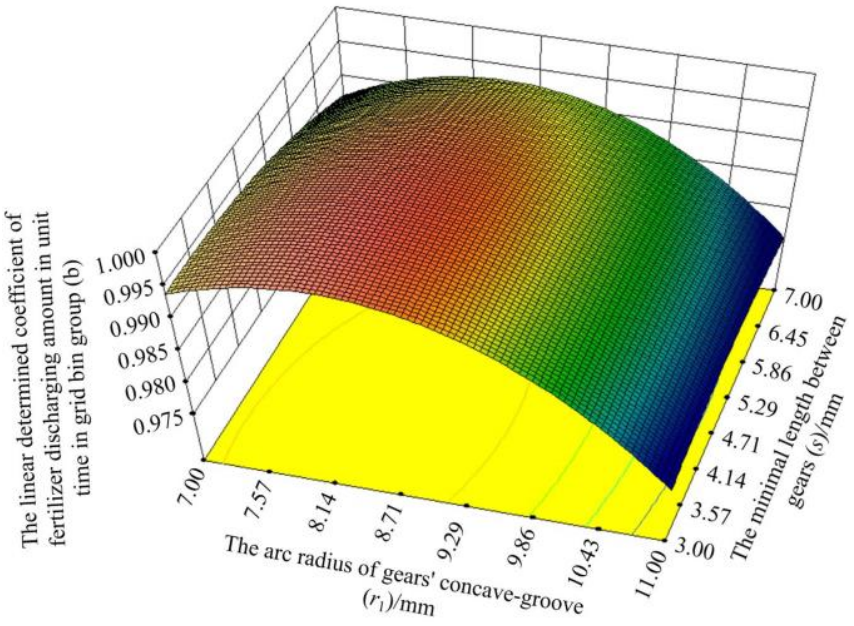

Figure 12 Response surface map of the minimal length between gears $(s)$ and the arc radius of gears' concave-groove $\left(r_{1}\right)$ to coefficient of determination 


\subsection{Optimum parameters verification}

Software Design-Expert 8.0 was applied to analyze data. The minimal discharging stability variation coefficient $(\sigma)$ in grid bin group (a) and the maximum determined coefficient of fertilizer discharging amount in unit time $\left(r^{2}\right)$ in grid bin (b) were chosen. The optimum parameters through Design-Expert 8.0 was obtained. The arc radius of gears' concave-grooves was $8.54 \mathrm{~mm}$ and the minimal length between two mutual meshing gears was $5.22 \mathrm{~mm}$. In this instance, the variation coefficient was 0.28 and the determined coefficient was 0.9972 .

To verify the fertilizer apparatus with optimum parameter performance, a bench test for fertilizer apparatus owned arc gears was executed in Northeast Forestry University, China. The test device is shown in Figure 13.
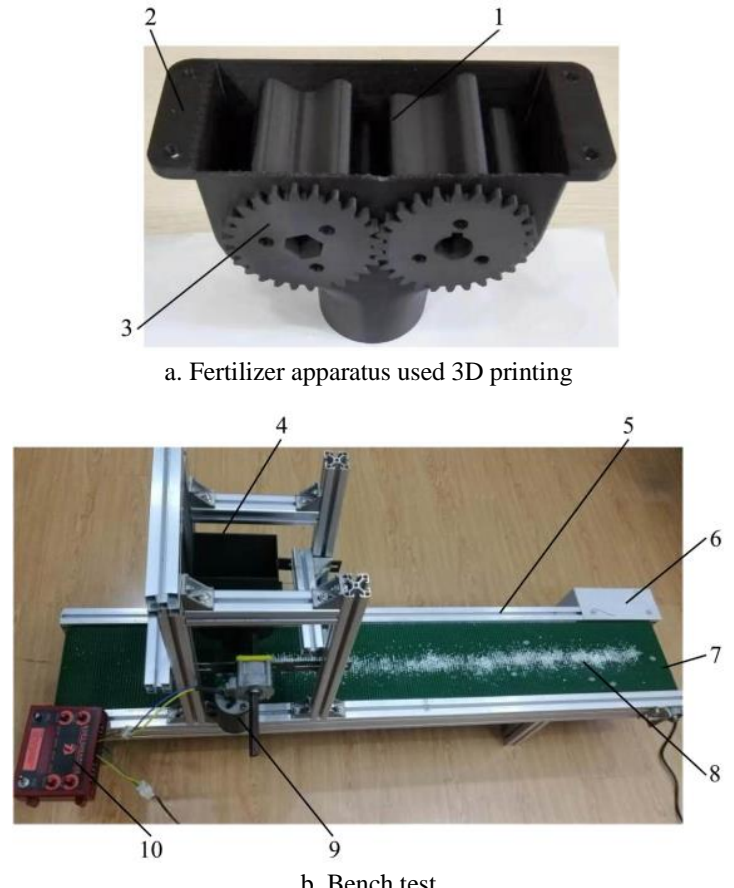

b. Bench test

1. Arc gears that discharges fertilizer 2. Shell 3. Cylindrical gears 4. Box placing fertilizer 5. Rack in experiment 6 . Electric machinery used to drive conveyor-belt 7. Conveyor-belt 8. Urea fertilizer particle 9. Electric machinery used to drive fertilizer apparatus 10 . Frequency transformer

Figure 13 3D printing model and bench test equipment

The bench test devices included experiment bench, stepping motor, fertilizer apparatus owned arc gears, fertilizer box and conveyor-belt. The performance of fertilizer apparatus verification test was developed by using the above bench test devices. The test fertilizer was drying urea, and $1 \mathrm{~kg}$ urea was put into fertilizer box. The rotational speed of arc gears discharging fertilizer was $40 \mathrm{r} / \mathrm{min}$, the velocity of conveyor-belt is $0.2 \mathrm{~m} / \mathrm{s}$, and test time is $10 \mathrm{~s}$. The conveyor-belt was divided into $10 \mathrm{~cm}$ long areas, and the mass of fertilizer discharged from each area was weighed. The discharging stability variation coefficient and the linear determined coefficient of fertilizer discharging amount in unit time were calculated according to Equations (25)-(29). Five replicates were set and the average value was taken as the test result. Test results indicated that the variation coefficient was 0.28 and the determination coefficient was 0.9972. Compare with the theoretical values, relative errors were $-3.57 \%$ and $0.08 \%$ respectively. The smaller relative errors showed that the bench test results were reliable.

In order to simulate the real field conditions and eliminate the influence of machine vibration on the test results, field simulation test was carried out. As shown in Figure 14, the experimenter pushed the machine by hand, and the fertilizer fell through the fertilizer apparatus owned arc gears and distributed in a strip. The fertilizer dropping area was divided into $10 \mathrm{~cm}$ long areas like bench test. The fertilizer mass in each area was weighed. The variation coefficient and determination coefficient were calculated. The field simulation test results are in good agreement with the bench test.

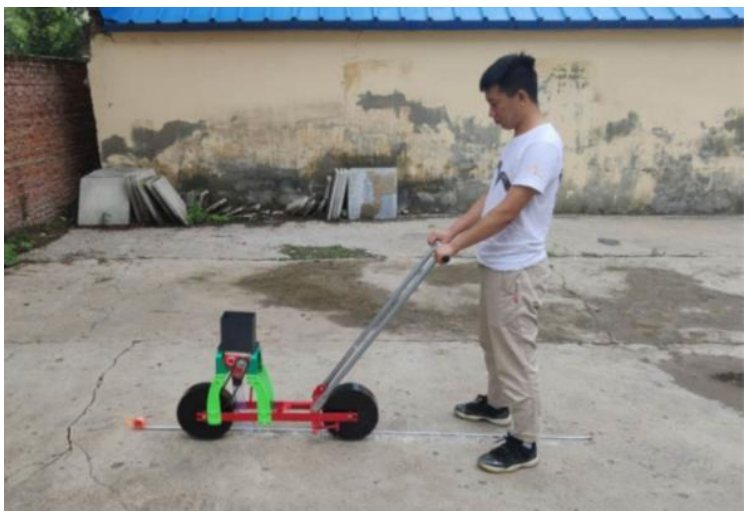

a. Field simulation test

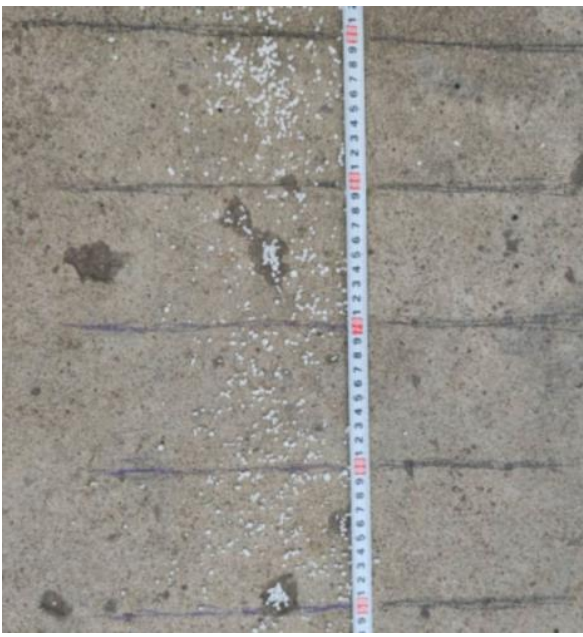

b. Diagram of divided grids

Figure 14 Field simulation test

Therefore, it is uniform for fertilizer apparatus owned arc gears with optimum parameters to discharge fertilizer in test results and it is in accord with requirements in filed fertilization.

\section{Conclusions}

A fertilizer apparatus owned arc gears was designed, and the structure parameters of the arc gears that discharged fertilizer was analyzed, and the influence of the arc structure parameter to the uniformity of fertilizer apparatus owned arc gears working performance was explored. In addition, this paper built the mathematics index relationship between the arc radius of gears' concave-grooves $\left(r_{1}\right)$, the minimal length between two mutual meshing gears $(s)$ and the uniformity of fertilizer apparatus working performance.

The discrete element method simulation application software called EDEM was utilized to simulate the working process of fertilizer apparatus owned arc gears, and the two factors and five levels quadratic rotation orthogonal experiment was applied. The results of experiment indicated that the arc radius of gears' concave-grooves had significant effect on the determined coefficient of fertilizer discharging amount in unit time, and the 
minimal length between two mutual meshing gears had significant effect on the variation coefficient of the stability of fertilizer discharging amount. The optimum structural parameters were $8.54 \mathrm{~mm}$ as the arc radius of gears' concave-grooves and $5.22 \mathrm{~mm}$ as the minimal length between two mutual meshing gears. Upon this circumstance, the variation coefficient was 0.28 , the determination coefficient was 0.9972 .

A fertilizer apparatus owned arc gears with the optimum structural parameters was produced. Bench test and field simulation test were tested. The results showed that the variation coefficient was 0.28 and the determination coefficient was 0.9972 . Compared with the theoretical values, relative errors were $3.57 \%$ and $0.08 \%$ respectively. The smaller relative errors showed that the bench test results and field simulation test were reliable. It was effective and reliable to simulate the working process of fertilizer apparatus owned arc gears by discrete element method.

\section{Acknowledgements}

The authors acknowledge that this work was financially supported by the National Key R\&D Plan, China (Grant No. 2018yfd0201001), the Fundamental Research Funds for the Central Universities, China (Grant No. 2572020BF03).

\section{[References]}

[1] Lu W C, Liu C. The "Environmental punishment" effect of fertilize pollution in grain crop production. China Environmental Science, 2017; 37(5): 1988-1994. (in Chinese)

[2] Liu Q P. Spatio-temporal changes of fertilization intensity and environmental safety threshold in China. Transactions of the CSAE, 2017; 33(6): 214-221. (in Chinese)

[3] Liang F, Yang G G, Xu F, Zhao H W, Ma L J, Cen G Y, et al. The seeding rate control system design and experiment of the external groove wheel seeder. Journal of Agricultural Mechanization Research, 2019; 41(10): 153-157. (in Chinese)

[4] Li K, Zhang L X, Zhang L P, Chu S Z, Qi X M, Qian Y, et al. Design and experiment of bivariate fertilizer. Journal of Gansu Agricultural University, 2016; 51(4): 128-133. (in Chinese)

[5] Dun G Q, Yu C L, Yang Y Z, Chen H T, Ji W Y, Ye J. Discharging characteristic test of outer-groove wheel fertilizer and parameter optimization of fertilizer tongue by discrete element simulation. Journal of Hunan Agricultural University, 2018; 44(6): 661-665. (in Chinese)

[6] Dun G Q, Chen H T, Feng Y N, Yang J L, Li A, Zha S H. Parameter optimization and test of key parts of fertilizer allocation device based on EDEM software. Transactions of the CSAE, 2016; 32(7): 36-42. (in Chinese)

[7] Yang Z, Zhu Q C, Sun J F, Chen Z C, Zhang Z W. Study on the performance of fluted roller fertilizer distributor based on EDEM and 3D printing. Journal of Agricultural Mechanization Research, 2018; 40(5): 175-180. (in Chinese)

[8] Zhang T, Liu F, Liu Y Q, Zhao M Q, Zhang S, Li N, et al. Discrete element simulation of outer groove wheel type fertilizer discharging device capacity analysis. Journal of Agricultural Mechanization Research, 2015; 37(9): 198-201. (in Chinese)

[9] Wang B T, Bai L, Ding S P, Yao Y X, Huang Y X, Zhu X R. Simulation and experimental study on impact of fluted-roller fertilizer key parameters on fertilizer amount. Journal of Chinese Agricultural Mechanization, 2017; 38(10): 1-6, 23. (in Chinese)

[10] Wang B T. Simulation and parameter optimization of the working process of the outer grooved wheel fertilizer distributor based on discrete element method. Master dissertation. Yangling: Northwest A\&F University, 2017. (in Chinese)

[11] Lv H. A new kind of method for the optimization design of outer groove-wheel fertilizer apparatuses. Doctoral dissertation. Jilin: Jilin University, 2014. (in Chinese)

[12] Lv H, Yu J Q, Fu H. Simulation of the operation a fertilizer spreader based on an outer groove wheel using a discrete element method. Mathematical and Computer Modeling, 2013; 58(3-4): 836-845.

[13] Liao Q X, Zhang P L, Liao Y T, Yu J J, Cao X Y. Numerical simulation on seeding performance of centrifugal rape-seed metering device based on EDEM. Transactions of the CSAM, 2014; 45(2): 109-114. (in Chinese)

[14] Hu J P, Guo K, Zhou C J, Hou C. Simulation and experiment of supplying seeds in box of magnetic precision cylinder-seeder. Transactions of the CSAM, 2014; 45(2): 109-114. (in Chinese)

[15] Yoshiyuki S, Cundall P A. Three dimensional DEM simulation of bulk handing by screw conveyors. Journal of Engineering Mechanics, 2001; 127(9): 864-872.

[16] Wang C J, Liu Q, Ma L Z, Li L. Cottonseed powder motion law in 3-DOF hybrid vibration screen surface. Transactions of the CSAE, 2015; 31(6): 49-56. (in Chinese)

[17] Chen J, Zhou H, Zhao Z, Li Y M, Gong Z Q. Analysis of rice seeds motion on vibrating plate using EDEM. Transactions of the CSAM, 2011; 42(10): 79-83, 100. (in Chinese)

[18] Wang G Q, Hao W J, Wang J X. Discrete element method and its application in EDEM. Northwest University of Technology Press, 2010; pp.21-22.

[19] Benn D I, Astrom J, Zwinger T. Melt-under-cutting and buoyancy-driven calving from tidewater glaciers: new insights from discrete element and continuum model simulations. Journay of Glaciology, 2017; 63(240): 691-702.

[20] Pamornnak B, Somchai L, Mitchai C. Oil content determination scheme of postharvest oil palm for mobile devices. Biosystems Engineering, 2015; 134: 8-19.

[21] Fang H M, Ji C Y, Zhang Q Y, Guo J. Force analysis of rotary blade based on discrete element method. Transactions of the CSAE, 2016; 32(21): 54-59. (in Chinese)

[22] He Y M, Wu M L, Xiang W, Yan B, Wang J Y, Bao P F. Application progress of discrete element method in agricultural engineering. Chinese Agricultural Science Bulletin, 2017; 33(20): 133-137. (in Chinese)

[23] Qiu Y B. Experimental design and data processing. China University of Science and Technology Press, 2008.

[24] Wang J F, Zou D T, Wang J W. Testing and analysis of the shear modulus of urea granules. Computer and Computing Technologies in Agriculture, 2013; 7(1): 137-144.

[25] Wen X Y, Jia H L, Zhang S W, Yuan H F, Wang G, Chen T Y. Test of suspension velocity of granular fertilizer based on EDEM-Fluent coupling. Transactions of the CSAM, 2020; 51(3): 69-77. (in Chinese)

[26] Adalarasan R, Santhanakumar M, Rajmohan M. Application of Grey Taguchi-based response surface methodology (GT-RSM) for optimizing the plasma arc cutting parameters of $304 \mathrm{~L}$ stainless steel. The International Journal of Advanced Manufacturing Technology, 2015; 78(5-8): 266-275.

[27] Zhou G X, Wang C, Zhang W, Liang Y, Li Y Q, Hu J. Mathematic model of deep-shovel with critical structure parameter based on two times orthogonal rotational regressive tests. Transactions of the CSAM, 2006; 2006(10): 86-89. (in Chinese) 